\title{
Fractionation of Cadmium, Lead and Copper in Municipal Solid Waste Incineration Bottom Ash
}

\author{
Adam Łukowski ${ }^{*}$, Joanna Irena Olejniczak ${ }^{2}$ \\ 1 Institute of Environmental Engineering and Energy Production, Department of Technology in Environmental \\ Engineering, Bialystok University of Technology, Wiejska 45A, 15-351 Białystok, Poland \\ 2 Doctoral student at Faculty of Civil Engineering and Environmental Sciences, Bialystok University of \\ Technology, Wiejska 45A, 15-351 Białystok, Poland \\ * Corresponding author's e-mail: a.lukowski@pb.edu.pl
}

\begin{abstract}
The basic physicochemical properties such as: dry mass, $\mathrm{pH}$, pseudo-total content of cadmium, lead and copper, were determined in the fresh bottom ash samples from a municipal waste incineration plant. In order to study fractional composition of the investigated heavy metals, the BCR method was used (F1 - acid soluble and exchangeable fraction, F2 - reducible fraction, F3 - oxidizable fraction, F4 - residual fraction). The average percentage of cadmium in particular fractions was as follows: F1 $(37.5 \%)>\mathrm{F} 4(27.2 \%)>\mathrm{F} 2(25.3 \%)>\mathrm{F} 3$ $(10.0 \%)$, for lead: F4 $(36.5 \%)>\mathrm{F} 2(27.2 \%)>\mathrm{F} 3(23.4 \%)>\mathrm{F} 1(12.9 \%)$, and in the case of copper F4(66.3\%) > $\mathrm{F} 3(22.1 \%)>\mathrm{F} 2(7.4 \%)>\mathrm{F} 1(4.2 \%)$. Among the studied metals, in mobile pool (F1-F3) the highest amount of cadmium was noted (72.8\%); for lead it was $63.5 \%$, and for copper $33.7 \%$ of the pseudo-total content.
\end{abstract}

Keywords: heavy metals, BCR method, metal fractions, MSWI bottom ash

\section{INTRODUCTION}

In all countries, the amount of municipal waste is constantly increasing, contributing to a significant deterioration of the natural environment [Raharjo et al., 2017; Husár et al., 2019; Nagendra et al., 2019]. The awareness of how important the care for the world around us is reaches a growing group of people. The selective collection of municipal waste (paper, glass, plastics, metals) has become widely used in households and workplaces. First, waste generation should be prevented or reduced; if it is not possible, the waste is recovered. The use of other recovery processes is only implemented when it is not possible to prepare it for reuse or recycling for technological reasons or it is not justified for ecological or economic reasons. The wastes that cannot be recovered should be disposed of, for example by incineration. This process reduces the volume of municipal waste disposed in landfills and enables the recovery of energy. However, the incineration of municipal solid waste causes the formation of secondary products, i.e. secondary wastes in the form of ashes of various types (bottom or fly ashes). The management of this material in a balanced manner is now an important issue because it contains heavy metals [Wielgosiński et al., 2014].

The goal of this study was the estimation of the fractional composition of heavy metals usually present in municipal solid waste incineration (MSWI) bottom ash, such as copper, cadmium and lead [Joseph et al., 2018] in particle size fraction $\leq 2 \mathrm{~mm}$, which contains the largest amounts of metals [Chimenos et al., 1999]. The metal content in fractions better reflects the environmental threats related to heavy metals, as compared to the total content. It describes which part of the total metal content can be mobilized due to the changes of the environmental factors (e.g. pH, redox potential, etc.). Heavy metals, depending on 
the content in individual forms are more or less mobile, i.e. bioavailable. In order to investigate the metal content in fractions, including cadmium, lead and copper in bottom ash, the sequential extraction method is used [Yao et al., 2011; Gonzales et al., 2019; Haberl and Schuster, 2019). There are various procedures for the fractionation of metals, although one of the most economical ones is the BCR method (proposed by Standards, Measurement and Testing Programme, former Community Bureau of Reference).

\section{MATERIALS AND METHODS}

\section{Sampling}

The fresh bottom ash samples from MSWI plant in Białystok (North Eastern Poland) were collected for a period of seven weeks in the year 2016. During this period, 11650 tons of wastes were incinerated (average calorific value $\left.8.95 \mathrm{MJ} \cdot \mathrm{kg}^{-1}\right)$. The wastes were incinerated in the stoker-fired furnace (temperature on the grate $-700^{\circ} \mathrm{C}$ ). The mixed municipal waste (from containers) and the waste after the sorting process are subjected to the thermal disposal.

Twenty samples were taken, approximately $1 \mathrm{~kg}$ each. The bottom ash was water quenched and separated magnetically to recover ferrous metals before sampling. The samples were sieved through a $2 \mathrm{~mm}$ sieve and ground in an agate mortar.

\section{Analysis of physicochemical properties}

Dry mass was evaluated by drying at $105^{\circ} \mathrm{C}$ to the constant mass. Pseudo-total $\mathrm{Cd}, \mathrm{Pb}$ and $\mathrm{Cu}$ content was determined by means of atomic absorption spectrometry with flame atomisation (FAAS), after previous microwave digestion $\left(0.5 \mathrm{~g}\right.$ of dry ash $\left.+10 \mathrm{~cm}^{3} \mathrm{HNO}_{3}+3 \mathrm{~cm}^{3} \mathrm{HClO}_{4}\right)$. The $\mathrm{pH}$ was determined with the potentiometric method (measured after 24 hours in suspension $5 \mathrm{~g}$ of ash in $25 \mathrm{~cm}^{3}$ of deionized water).

\section{Sequential extraction procedure}

The BCR method with the usage of ultrasonic probe Sonics VCX 130 was used to evaluate fractional composition of cadmium, lead and copper in the dry MSWI bottom ash samples. The extraction included four stages [Łukowski, 2017]:

1. The acid soluble and exchangeable fraction
(F1) $-1 \mathrm{~g}$ of ash in $100 \mathrm{~cm}^{3}$ centrifuge tube with $40 \mathrm{~cm}^{3}$ of $0.11 \mathrm{~mol} \cdot \mathrm{dm}^{-3}$ acetic acid was sonicated for 7 minutes (power $-20 \mathrm{~W}$ ) at a temperature of $22 \pm 5^{\circ} \mathrm{C}$. Then, the mixture was centrifuged for 20 minutes at $3000 \mathrm{~g}$. The extract was separated for analysis. The residue with $20 \mathrm{~cm}^{3}$ of deionized water was sonicated for 5 minutes (power - 20W) and centrifuged for 20 minutes at $3000 \mathrm{~g}$. Water was discarded.

2. The reducible fraction, bound to $\mathrm{Fe} / \mathrm{Mn}$ oxides (F2) $-40 \mathrm{~cm}^{3}$ of $0.5 \mathrm{~mol} \cdot \mathrm{dm}^{-3}$ hydroxylamine hydrochloride fresh solution, $\mathrm{pH} 1.5$ was added to the residue from the first step, and sonicated for 7 minutes (power - 20W) at a temperature of $22 \pm 5^{\circ} \mathrm{C}$. Then, the mixture was centrifuged for 20 minutes at $3000 \mathrm{~g}$. The extract was separated for analysis. The residue was rinsed with deionized water, like in the first step.

3 . The oxidizable fraction, bound to organic matter (F3) $-20 \mathrm{~cm}^{3}$ of $30 \%$ hydrogen peroxide was added to the residue from the second step and sonicated for 2 minutes (power $-20 \mathrm{~W}$ ) at the temperature of $22 \pm 5^{\circ} \mathrm{C}$. Then, the volume of $\mathrm{H}_{2} \mathrm{O}_{2}$ was reduced to approx. $1 \mathrm{~cm}^{3}$ using water bath. Afterwards, $50 \mathrm{~cm}^{3}$ of $1 \mathrm{~mol} \cdot \mathrm{dm}^{-3}$ ammonium acetate was added to the moist residue and sonicated for $6 \mathrm{~min}$. (power $-20 \mathrm{~W}$ ) at a temperature of $22 \pm 5^{\circ} \mathrm{C}$. Then, the mixture was centrifuged for 20 minutes at $3000 \mathrm{~g}$. The extract was separated for the analysis. The residue was rinsed with deionized water, like in the previous steps.

The determination of cadmium, copper and lead content in fractions was carried out by FAAS. The percentage of particular fractions of cadmium, copper and lead in the pseudo-total content and the percentage of mobile pool (F1 - F3) were calculated. The content of $\mathrm{Cd}, \mathrm{Cu}$ and $\mathrm{Pb}$ in the residual fraction (F4) was calculated from the difference between the pseudo-total contents and the contents in the F1-F3 fractions.

\section{RESULTS AND DISCUSSION}

\section{Physicochemical properties of MSWI bottom ash}

The average dry mass content was $77.5 \%$ and ranged from 74.0 to 84.1 (Table 1). The obtained results are generally in accordance with those given by Wiles [1996], who stated that bottom ash contains usually from $15 \%$ to $25 \%$ of water 
and the moisture is essential to control fugitive dust and to reduce the volume of ash.

One of the most important chemical properties of ash is $\mathrm{pH}$. It is one of the main factors influencing the metal leaching. The MSWI bottom ash utilization is mainly dependent on the hazards of heavy metal contamination [Quek et al., 2016]. The average $\mathrm{pH}$ value in the studied MSWI bottom ash was 11.79. A similar $\mathrm{pH}$ for the municipal solid waste incineration bottom ash is given by Yao et al. [2011] and Yao et al. [2012], 11.2 and 10.85 respectively. Moreover, according to Dijkstra et al. [2006], the fresh bottom ash samples are mainly alkaline $(\mathrm{pH}=10-12)$.

The least pseudo-total content among the studied metals was noted in the case of cadmium $\left(1.48 \mathrm{mg} \mathrm{kg}^{-1}\right)$ and the highest for copper (1135.0 $\mathrm{mg} \cdot \mathrm{kg}^{-1} \mathrm{DM}$ on average). As stressed by Dou et al. [2017], based on the data from around the world, the MSWI bottom ash contains approximately $100-10000 \mathrm{mg} \mathrm{kg}^{-1}$ of $\mathrm{Cu}$ and $\mathrm{Pb}$ as well as $1-100$ $\mathrm{mg} \mathrm{kg}^{-1}$ of Cd. Chimenos et al. [1999], emphasized that copper and lead accumulate mainly in the 1-2 $\mathrm{mm}$ particle size fraction of municipal waste. According to these authors, the highest amounts of copper and lead in this fraction are associated with small parts of copper wires and alloys used for soldering. The wide range of pseudo-total metal contents in the studied bottom ash is probably caused by the variable composition of municipal waste.

\section{Fractionation of metals in MSWI bottom ash}

The F1 fraction accumulated the largest amount of cadmium, $0.55 \mathrm{mg}^{\cdot} \mathrm{kg}^{-1}$, on average (Table 2). It was $37.5 \%$ of pseudo-total content (Figure 1) at the range from 12.4 to $62.4 \%$. As stated by Kouassi et al. [2014], under neutral or slightly acidic conditions, the metals in this fraction can be leached very easily. It means that the $\mathrm{Cd}$ contained in fresh MSWI bottom ash poses a major environmental and human health problem, despite its lowest pseudo-total content among the studied metals. This also emerges from the well-known high toxicity of cadmium and the large scale of bottom ash production. Such a high content in exchangeable and acid soluble fraction must result from the properties of cadmium, which is considered as volatile element. According to Yao et al. [2013], most of $\mathrm{Cd}$ in fine fraction of ash originates from evaporation. The evaporated $\mathrm{Cd}$ is reacting with $\mathrm{CO}_{2}$ in the furnace, thus creating carbonates. Additionally, the mobile pool of cadmium ( $72.8 \%$ at the range from 37.2 to $97.2 \%$ of pseudo-total content), was the highest in comparison with the lead and copper. That intensifies the threats connected with the $\mathrm{Cd}$ leaching under changing environmental conditions. The metals present in the F2 fraction are dependent on the redox potential changes and can be mobilized under reducible conditions or by low level of oxygen. The metals from the F3 fraction would be released by oxidizable conditions [Pöykiö et al., 2016].

Table 1. Physicochemical characteristics of MSWI bottom ash $(n=20)$

\begin{tabular}{|c|c|c|c|c|c|}
\hline \multirow{2}{*}{$\begin{array}{c}\text { Bottom ash } \\
\text { samples }\end{array}$} & \multirow{2}{*}{$\mathrm{DM}$} & \multicolumn{3}{|c|}{ Pseudo-total content $\left[\mathrm{mg}^{\mathrm{kg}} \mathrm{kg}^{-1} \mathrm{DM}\right]$} \\
\cline { 4 - 6 } & & $\mathrm{pH}$ & $\mathrm{Cd}$ & $\mathrm{Pb}$ & $\mathrm{Cu}$ \\
\hline min $-\max$ & $74.0-84.1$ & $10.96-12.66$ & $0.47-4.35$ & $42.4-743.1$ & $311.5-2342.1$ \\
\hline mean \pm SD & $77.5 \pm 3.1$ & $11.79 \pm 0.47$ & $1.48 \pm 1.04$ & $190.9 \pm 147.5$ & $1135.0 \pm 704.2$ \\
\hline
\end{tabular}

Table 2. The content of cadmium, lead and copper in the fractions in MSWI bottom ash

\begin{tabular}{|c|c|c|c|}
\hline Metal & Fraction & Min - Max & Mean \pm SD, $\mathrm{n}=20$ \\
\hline \multirow{3}{*}{$\begin{array}{c}\mathrm{C} d \\
\left(\mathrm{mg}^{\mathrm{kg}}{ }^{-1} \mathrm{DM}\right)\end{array}$} & $\mathrm{F} 1$ & $0.11-1.57$ & $0.55 \pm 0.36$ \\
\cline { 2 - 4 } & $\mathrm{F} 2$ & $0.03-1.17$ & $0.37 \pm 0.29$ \\
\cline { 2 - 4 } & $\mathrm{F} 3$ & $0.02-0.84$ & $0.15 \pm 0.18$ \\
\cline { 2 - 4 } & $\mathrm{F} 4$ & $0.01-1.62$ & $0.40 \pm 0.48$ \\
\hline \multirow{3}{*}{$\begin{array}{c}\mathrm{Pb} \\
\left(\mathrm{mg}^{-1} \mathrm{DM}\right)\end{array}$} & $\mathrm{F} 1$ & $0.94-230.76$ & $24.63 \pm 54.98$ \\
\cline { 2 - 4 } & $\mathrm{F} 2$ & $14.38-190.23$ & $51.91 \pm 43.80$ \\
\cline { 2 - 4 } & $\mathrm{F} 3$ & $11.45-127.93$ & $44.59 \pm 30.58$ \\
\hline \multirow{3}{*}{$\begin{array}{c}\mathrm{Cu} \\
\left(\mathrm{mg}^{\mathrm{kg}}{ }^{-1} \mathrm{DM}\right)\end{array}$} & $\mathrm{F} 4$ & $6.10-236.38$ & $69.72 \pm 61.17$ \\
\cline { 2 - 4 } & $\mathrm{F} 1$ & $2.49-163.79$ & $87.37 \pm 31.29$ \\
\cline { 2 - 4 } & $\mathrm{F} 2$ & $5.92-224.48$ & $251.06 \pm 146.12$ \\
\cline { 2 - 4 } & $\mathrm{F} 3$ & $43.98-543.15$ & $752.03 \pm 704.04$ \\
\hline
\end{tabular}




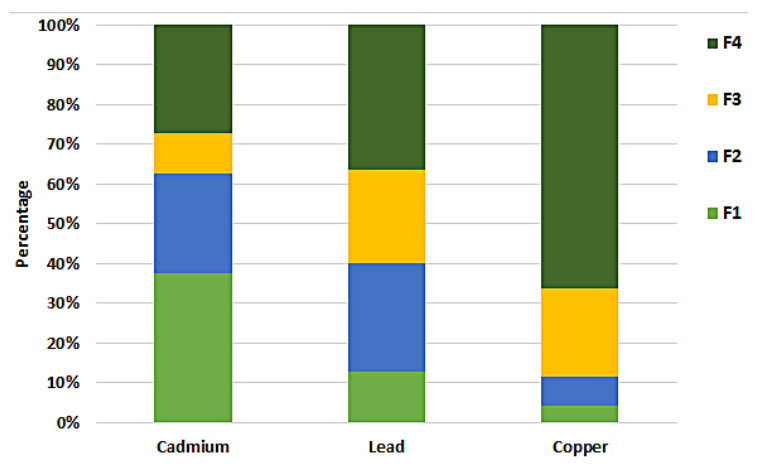

Figure 1. Average percentage of $\mathrm{Cd}, \mathrm{Pb}$ and $\mathrm{Cu}$ in fractions in MSWI bottom ash

The F4 Fraction gathered the lowest amount of cadmium (27.2\%) as compared to the rest of metals. It is the result of high volatility, mentioned above. It was confirmed by the percentage of lead (36.5\%) and copper (66.3\%) in this fraction, since $\mathrm{Pb}$ is less volatile than $\mathrm{Cd}$ [Zhou et al., 2019] and $\mathrm{Cu}$ is less volatile than $\mathrm{Pb}$ [Ke et al., 2017]. The share of $\mathrm{Cd}$ in the $\mathrm{F} 2$ fraction ( $25.3 \%$ on average) was similar in comparison with $\mathrm{Pb}(27.2 \%$ on average). Fraction F3 gathered $10.0 \%$ of Cd. It was the lowest amount of metal in this fraction among studied metals.

The highest amount of lead, $69.72 \mathrm{mg} \cdot \mathrm{kg}^{-1}$ on average, was found in the $\mathrm{F} 4$ fraction. It was $36.5 \%$ of pseudo-total content at the range from 4.6 to $69.0 \%$. Additionally, Yao et al. [2010] confirmed the largest $\mathrm{Pb}$ percentage in the residual fraction. On the basis of the research on the MSWI bottom ash originated from six incineration plants in the Zhejiang province (China), the authors noted more than $50 \%$ of $\mathrm{Pb}$ in this fraction. The lead in the residual fraction is bound to the calcio-alumino-silicate phases [Gonzales et al. 2019]. The percentage of $\mathrm{Pb}$ in the $\mathrm{F} 2$ and F3 fractions was similar, 27.2 and $23.4 \%$ respectively. The content of lead in the fraction bound to the $\mathrm{Fe} / \mathrm{Mn}$ oxides was the highest among studied metals. The mobile pool of $\mathrm{Pb}$ gathered $63.5 \%$ of pseudo-total content and ranged from 24.6 to $95.4 \%$. It is in good accordance with the results of Pöykiö et al. [2016] who stated about $69.4 \%$ of lead in the F1-F3 fractions.

Similarly, like in the case of $\mathrm{Pb}$, the largest content of copper, $752.03 \mathrm{mg} \cdot \mathrm{kg}^{-1}$ on average, was noted in the F4 fraction. That comprised $66.3 \%$ of pseudo-total content and ranged from 10.2 to $89.2 \%$. It was also the highest share among all the fractions of the investigated metals.

According to Yao et al. [2013], the $\mathrm{Cu}$ in the MSWI bottom ash is mostly present in the residual fraction. For the bottom ash fractions of $<0.45 \mathrm{~mm}, 0.45-1 \mathrm{~mm}$ and $1-2 \mathrm{~mm}$ they noted $69.2 \%, 64.6 \%$ and $66.3 \%$ of copper, respectively. The residual fraction is chemically stable and biologically inactive. It mainly includes the metals embedded in the crystal lattice of primary and secondary minerals which are the part of the ash from the incineration of municipal waste. It consists mainly of silicate and aluminosilicate minerals. Under natural conditions, excluding the influence of unfavourable external factors, they can be considered permanently immobilized. In the F1 fraction, we stated the lowest share of copper ( $4.2 \%$ on average). It was also the lowest amount among all the fractions of studied metals. The F2 fraction gathered $7.4 \%$ of pseudo-total copper, the least as compared to lead and cadmium. Organic matter bound fraction (F3) comprised 22.1 $\%$ of pseudo-total copper on average. Copper is known from strong affinity to organic matter. It forms complexes with organic ligands, e.g. fulvic acid [Yao et al., 2011]. This is confirmed by the low amount of $\mathrm{Cu}$ in the first two fractions, as stated above. The most of the organic matter from municipal solid waste is damaged through the incineration process [Yao et al., 2010]. According to Chimenos et al. [1999], the unburned organic matter in the 1-2 mm fraction of MSWI bottom ash comprises below $4 \%$ of weight. In the mobile pool of $\mathrm{Cu}$, we found only $33.7 \%$ of pseudo-total content at the range from 10.8 to $89.8 \%$. It was the lowest total content in the F1-F3 fractions among investigated heavy metals, suggesting the least risk of metal leaching.

\section{CONCLUSIONS}

1. The highest percentage of metal in acid soluble and exchangeable fraction (most mobile) was noted in the case of cadmium.

2. The average cadmium content in particular fractions can be arranged in the following order: F1 $(37.5 \%)>\mathrm{F} 4(27.2 \%)>\mathrm{F} 2$ $(25.3 \%)>$ F3 $(10.0 \%)$; for lead: F4 $(36.5 \%)>$ $\mathrm{F} 2(27.2 \%)>\mathrm{F} 3(23.4 \%)>\mathrm{F} 1(12.9 \%)$ and for copper: F4(66.3\%) > F3(22.1\%) > F $2(7.4 \%)>$ F1(4.2\%).

3. Assuming the summary percentage of metal in mobile fractions (F1-F3) as the solubility criterion, we can state that cadmium was the most soluble and copper the least soluble. 


\section{Acknowledgements}

The investigations were carried out within the work No. WZ/WBiIŚ/8/2019 at Bialystok University of Technology and subsidized by the Minister of Science and Higher Education.

\section{REFERENCES}

1. Chimenos J.M., Segarra M.. Fernandez M.A., Espiell F. 1999. Characterization of the bottom ash in municipal solid waste incinerator. Journal of Hazardous Materials, 64, 211-222.

2. Dijkstra J.J., van der Sloot H. A., Comans R.N.J. 2006. The leaching of major and trace elements from MSWI bottom ash as a function of $\mathrm{pH}$ and time. Applied Geochemistry, 21, 335-351.

3. Dou X., Ren F., Nguyen M.Q., Ahamed A., Yijn K., Chan W.P., Chang V. W-C. 2017. Review of MSWI bottom ash utilization from perspectives of collective characterization, treatment and existing application. Renewable and Sustainable Energy Reviews, 79, 24-38.

4. Gonzales M.L., Blanc D., de Brauer C. 2019. Multi-Analytical approach and geochemical modeling for mineral trace element speciation in MSWI bottom-ash. Waste and Biomass Valorization, 10, 547-560.

5. Haberl J., Schuster M. 2019. Solubility of elements in waste incineration fly ash and bottom ash under various leaching conditions studied by a sequential extraction procedure. Waste Management, 87, 268-278.

6. Husár J., Haydary J., Šuhaj P., Steltenpohl P. 2019. Potential of tire pyrolysis char as tar-cracking catalyst in solid waste and biomass gasification. Chemical Papers, 73, 2091-2101.

7. Joseph A.M., Snellings R., Van den Heede P., Matthys S., De Belie N. 2018. The use of municipal solid waste incineration ash in various building materials: a Belgian point of view. Materials, 11, 141-171.

8. Ke C., Ma X., Tang Y., Zheng W., Wu Z. 2017. The volatilization of heavy metals during co-combustion of food waste and polyvinyl chloride in air and carbon dioxide/oxygen atmosphere. Bioresource Technology 244, 1024-1030.

9. Kouassi N.L.B., Yao K.M., Trokourey A., Soro M.B. 2014. Preliminary assessment of cadmium mobility in surface sediments of a tropical estuary. Bulletin of the Chemical Society of Ethiopia, 28(2), 245-254.

10. Łukowski A. 2017. Fractionation of heavy metals
$(\mathrm{Pb}, \mathrm{Cr}$ and $\mathrm{Cd})$ in municipal sewage sludges from Podlasie Province. Journal of Ecological Engineering, 18(1), 132-138.

11. Nagendra B., Lakshmisha A., Agarwal P. 2019. Mobile application in municipal waste tracking: a pilot study of "PAC waste tracker" in Bangalore city. India. Journal of Material Cycles and Waste Management, 21, 705-712.

12. Pöykiö R., Mäkelä M., Watkins G., Nurmesmeni H., Dahl O. 2016. Heavy metals leaching in bottom ash and fly ash fractions from industrial-scale BFB-boiler for environmental risks assessment. Transactions of Nonferrous Metals Society of China, 26, 256-264.

13. Quek A., Xu W., Guo L., Wu D. 2016. Heavy metal removal from incineration bottom ash through washing with rainwater and seawater. International Journal of Waste Resources, 6(1), doi:10.4172/2252-5211.1000203

14. Raharjo S., Matsumoto T., Ihsan T., Rachman I., Gustin L. 2017. Community-based solid waste bank program for municipal solid waste management improvement in Indonesia: a case study of Padang city. Journal of Material Cycles and Waste Management, 19, 201-212.

15. Wielgosiński G., Wasiak D., Zawadzka A. 2014. The use of sequential extraction for assessing environmental risks of waste incineration bottom ash. Ecological Chemistry and Engineering, 21(3), 413-423.

16. Wiles C. C. 1996. Municipal solid waste combustion ash: state-of-the-knowledge. Journal of Hazardous Materials, 47, 325-344.

17. Yao J., Kong Q., Zhu H., Long Y., Shen D. 2013. Content and fractionation of $\mathrm{Cu}, \mathrm{Zn}$ and $\mathrm{Cd}$ in size fractionated municipal solid waste incineration bottom ash. Ecotoxicology and Environmental Safety, 94, 131-137.

18. Yao J., Li W., Kong Q., Xia F., Shen D. 2012. Effect of weathering on the mobility of zinc in municipal solid waste incinerator bottom ash. Fuel, 93, 99-104.

19. Yao J., Li W., Xia F., Wang J., Fang C., Shen D. 2011. Investigation of $\mathrm{Cu}$ leaching from municipal solid waste incinerator bottom ash with a comprehensive approach. Frontiers in Energy, 5(3), 340-348.

20. Yao J., Li W., Kong Q., Wu Y., He R., Shen D. 2010 Content, mobility and transfer behavior of heavy metals in MSWI bottom ash in Zhejiang province, China. Fuel, 89, 616-622.

21. Zhou L., Guo H., Wang X., Chu M., Zhang G., Zhang L. 2019. Effect of occurrence mode of heavy metal elements in a low rank coal on volatility during pyrolysis. International Journal of Coal Science \& Technology, 6(2), 235-246. 